\title{
Gendered cities: Studying urban gender bias through street names
}

\section{Citation information:}

Gutiérrez-Mora D, Oto-Peralías D. Gendered cities: Studying urban gender bias through street names. Environment and Planning B: Urban Analytics and City Science. February 2022. doi:10.1177/23998083211068844

\begin{abstract}
This paper uses text analysis to measure gender bias in cities through the use of street names. Focusing on the case of Spain, we collect data on 15 million street names to analyze gender inequality in urban toponyms. We calculate for each Spanish municipality and each year from 2001 to 2020 a variable measuring the percentage of streets with female names over the total number of streets with male and female names. Our results reveal a strong gender imbalance in Spanish cities: the percentage of streets named after women is only $12 \%$ in 2020 . We also observe substantial intra-urban differences, with female named streets being relatively scarcer in town centers. Concerning new streets, gender bias is lower but still far from parity. The second part of the paper analyzes the correlation of our indicator of gender bias in street names with variables related to gender attitudes and values, with the results suggesting that it constitutes a useful cultural measure of gender equality at the city level. This study thus helps to measure a relevant phenomenon, given the strong symbolic power attributed to street names, which has been elusive to quantify so far.
\end{abstract}

Keywords: Street names, toponyms, cities, quantitative analysis, gender inequality, women

Dolores Gutiérrez-Mora, Universidad de Sevilla, Departamento de Historia, Teoría y Composición Arquitectónicas, Escuela Técnica Superior de Arquitectura. Av. Reina Mercedes, 2, Seville, 41012, Spain.

Daniel Oto-Peralías, Universidad Pablo de Olavide, Departamento de Economía, Métodos Cuantitativos e Historia Económica. Carretera de Utrera, Km. 1, Seville, 41013, Spain. E-mail: dotoper@upo.es (corresponding author).

Acknowledgements: We are particularly indebted to Seraphim Alvanides (Editor) and four anonymous referees of this journal for valuable comments and suggestions that led to a substantial improvement of the original manuscript. We also thank conference participants at the European Regional Science Association Conference (Lyon, 2019), IX Jornadas Arte y Ciudad: Visiones Urbanas (Madrid, 2020), 2nd Monash-Warwick-Zurich Text-as-Data Workshop (2021), and seminar participants at the Universidad Pablo de Olavide, University of St Andrews, Universidad Pública de Navarra, Cardiff Business School, and Joint Research Center of the European Commission in Seville for valuable comments and suggestions. José A. Torralbo Moreno provided excellent research assistance. Financial support by the Spanish Ministry of Science, Innovation and Universities through grant ECO2017-86780-R (AEI/FEDER, UE), Junta de Andalucía through I+D+i project P20_00808, and UPO-1380998 (FEDER) is gratefully acknowledged. 


\section{Introduction}

Streets named after men vastly outnumber those named after women. How large is this gender bias in our cities? To what extent does it vary across time and space? Are our cities becoming more egalitarian in this sphere? Does this bias reflect the view of the population towards gender roles? The aim of this article is to develop a methodology to quantify gender bias in street names through computational tools of text analysis. By doing so, we construct a geographic-specific and time-variant indicator of female share in street names that helps us answer these questions, and consequently, study the geographic variability of the phenomenon, its evolution over time, and its explanatory factors. ${ }^{1}$

Street names carry a strong symbolic power and are very present in our everyday life. In addition to their physical presence on street signs, they are constantly used in ordinary situations. An apparently mundane facet of urban management, "street naming systems also make up the very foundations of urban spatial imaginaries" (Rose-Redwood et al., 2018, p. 309). Although not commonly noticed, they exert a subtle but constant influence, naturalizing the social and cultural meanings inscribed on them (Azaryahu, 1996; Rose-Redwood et al., 2010). Gender bias in street names should therefore not be overlooked, and there are indeed numerous social initiatives across countries pursuing a more egalitarian presence of women in the cityscape (Bigon and Zuvalinyenga, 2021).

We collect data on 15 million street names in Spain to analyze gender inequality in urban toponyms. We calculate for each Spanish municipality and each year from 2001 to 2020 a variable measuring the percentage of streets with female names over the total number of streets with male and female names, which we call "female share". A crucial feature of our methodology is the development of a classifier algorithm to be able to compute such an indicator for a large sample of spatial units (municipalities), on a large territorial scale (a whole country, or potentially several of them), and at a yearly basis, which represents a major progress regarding what has been done so far. This allows comparative studies across cities, as well as tracking them over time.

Our results reveal a strong gender imbalance in Spanish cities: the female share in streets named after a person goes from $9.6 \%$ in 2001 to $12.1 \%$ in 2020 . These aggregate values hide a lot of spatial variation. Focusing on provincial capitals, the indicator ranges from 5.9\% (Tarragona) to $20.6 \%$ (Jaén). Concerning new and renamed streets, gender bias is lower but still very far from parity as the female share is $18.4 \%$ for the whole period, and again with a wide geographic variation. We also find a strong intra-urban spatial pattern, with the proportion of female streets increasing by more than half as we move away from the town center.

The second part of the paper analyzes the relationship of our indicator of gender bias in street names with variables related to gender attitudes and values. We find that municipalities with a higher female share in street names tend to have larger, better educated and younger populations, larger service sectors, more separations and divorces, and lower gender gaps in labor force activity

\footnotetext{
${ }^{1}$ An earlier version of this paper is available as a pre-print (Gutiérrez-Mora and Oto-Peralías, 2021).
} 
rate, education and housework. In addition, people living in towns with a higher female share have on average more egalitarian gender views. Interestingly, we further show that provinces with a higher female share have also historically had more prominent women.

The low proportion of women in the streetscape constitutes further evidence of their underrepresentation in the public sphere. This exclusion not only reflects a historical and cultural fact, but also contributes to its perpetuation by making the presence of male names more 'natural' in daily life. In addition, their symbolic marginalization leads to feelings of exclusion, revealed through interviews and by the existence of social movements (Bigon and Zuvalinyenga, 2021). The female share indicator can be a useful tool for a more just urban management policy in order to monitor progress towards an inclusive urban toponymy. Such a policy contributes to the UN Millennium Development Goals of gender equality, empowerment of women, and more inclusive and safer cities. Likewise, the proposed measure is a valuable resource for toponymic activist efforts to achieve a greater integration of women into the streetscape.

From a research perspective, the female share indicator constitutes a useful measure for the analysis of factors favoring women-friendly policies at the local level. Moreover, it can also be used as a proxy for cultural attitudes towards gender roles, expanding the possibilities of analysis with this novel measure. While this article focuses on the Spanish street map, the proposed methodology of measuring gender bias in street names on a large scale is applicable elsewhere.

The remainder of the paper is organized as follows. Section 2 presents a brief overview of the related literature, while Section 3 provides some social and political background. Section 4 discusses the methodology for the construction of the female share indicator and tests its validity. Section 5 presents the main results of the indicator as well as its correlation with variables related to gender inequality. Finally, Section 6 puts forward some implications and concludes.

\section{Related literature on commemorative street names and gender}

This study uses a research methodology that applies text analysis to urban toponyms in order to measure sociocultural phenomena at the local level (Oto-Peralías, 2018). Street names are not random; they represent cultural markers of a city and its history. Street names reflect the commemorative decisions of municipalities over time and, as such, can be understood as a "manifesto" about its cultural, social and political values (Rose-Redwood et al., 2010). Building on these insights, Oto-Peralías (2018) proposes the use of the information contained in street names to measure cultural variables at the city level. Focusing on religiosity, he shows that the population in Spain in areas with a higher percentage of religious streets tends to have stronger religious beliefs and behaviors, which supports the existence of a relationship between street names and the population cultural values. These findings appear to apply to other countries as well. For instance, in Scotland, people living in areas with street names commemorating Great Britain are less likely to identify themselves as Scottish only (Oto-Peralías, 2017). ${ }^{2}$

2 This line of research is related to recent work studying the evolution of ideological commemorative street names from a quantitative approach (Fabiszak et al., 2021; Alvanides et al., 2021; Rusu, 2020). 
Beyond the usefulness of urban toponyms to measure cultural values, the critical geographic literature attributes a strong symbolic power to them. This branch of the literature focuses on the process of naming and its implications. That process, according to Rose-Redwood et al. (2010), "sheds light on power relations-how some social groups have the authority to name while others do not-and the selective way in which such relations reproduce the dominance of certain ideologies and identities over others" (p. 462). Street names introduce a version of history and cultural values into the common space of everyday life and, therefore, can contribute to the reproduction of this narrative, becoming powerful instruments for legitimizing the status quo (Azaryahu, 1996). This symbolic power is reflected in the frequent renaming of streets that accompanies important political changes, by which political regimes seek to "naturalize" their authority (González-Faraco and Murphy, 1997; Palonen, 2008; Drozdzewski, 2014).

Given the strong symbolic power of street names, the representation of all sectors of the population has a crucial role for their social inclusion (Lombardo and Meier, 2018), and the lack of symbolic representation gives rise to unfriendly "commemorative atmospheres" that may affect their socio-psychological well-being (Alderman, 2020). Ethnicity, class, gender, sexuality, etc., have been and are reasons for exclusion at the symbolic representative level (Berg and Kearns, 1996; Tretter, 2011; McDowell, 2008; Forrest, 2018).

The fact that commemorative street names express the ruling socio-political order and that marginalized groups are underrepresented is hardly surprising, but the exclusion of women from the cityscape is particularly shocking because they are not a minority but half of the population. Why is the power to name, remember and identify public space so masculinized? Women have historically been excluded from public life, towards the private sphere. As a result, their work has been less known and recognized, making it more difficult to be present in the public realm. In this regard, according to the dataset of biographies of famous people Pantheon 2.0 (Yu et al., 2016), only $14 \%$ of famous figures born before 1950 are women. This can explain much of the current situation given the high weight that historical inertia has in street names.

Moreover, the traditional absence of women from political representative institutions (including city councils) also helps explain the current discriminatory toponymy. One example of marginalization of women's names comes from the official narratives that follow armed conflicts seeking to reinforce national identity through commemorative street names. In these cases, female identities tend to be considered of secondary importance and women protagonists are generally forgotten, which is largely because naming decisions are taken by male-dominated groups (McDowell, 2008; Mamvura et al., 2018). We can therefore contend that historical inertia and low presence of women in decision-making roles -along with a still patriarchal culture- are the main factors behind gender bias in place names.

As the critical toponymic scholarship has discussed, the overrepresentation of male names in the cityscape not only reflects a historical and cultural fact; it can also contribute to its perpetuation

It also relates to articles that study regional identity through traces such as town and business names (Cooper and Knotts, 2010; Fuchs, 2015; Liesch et al., 2015; Weaver and Holtkamp, 2016). 
by making the presence of male names to be more "natural" in the public sphere. ${ }^{3}$ This male predominance can aggravate a certain feeling of exclusion from the urban space, affecting "the urban political experience and emotional well-being of women" (Bigon and Zuvalinyenga, 2021, p. 227). Understandably, there is a reaction to this unfair situation: the desire of (symbolic) empowerment and reclaiming of the public space, channeled through social movements that promote a greater presence of women in street names. ${ }^{4}$

Finally, concerning studies focusing on gender inequality in toponyms, most of them are case studies of specific cities that reveal a large gender bias in street names. Interestingly, studies of cultures as different as Madrid, Buenos Aires and Anping conclude that gendered street names contribute to the persistence and reinforcement of gender stereotypes, that is, the traditional perception of the female role in society (Fernández, 2004; Yu, 2014; Cavalo, 2019). Moreover, these works show that women are not only quantitatively under-represented, but also qualitatively in the hierarchy of the urban network (with female names being relatively more frequent in secondary streets and the periphery).

\section{Place naming and gender relations in Spain}

Spain has experienced a turbulent political past in the last century, with several regime changes that have left their imprints on the street map (González Faraco and Murhpy, 1997; Capdepón, 2020). After the transition to democracy (1975-78), the newly formed democratic local governments found their towns overcrowded with Francoist street names. While many of those names were promptly replaced, a law was necessary thirty years later to fully remove Francoist symbols (Law 52/2007 of Historical Memory), creating a process of toponymic changes that have generated a strong social, political, and even legal controversy (Capdepón, 2020).

Just like street names reflect the values of the political regime in place, other sociocultural dimensions of society are reflected too, notably, the public predominance of men over women. The latter have been historically relegated to the private domain, particularly under the Francoist regime with its strong conservative Catholic values (Bustelo, 2016). Female employment rates in Spain were among the lowest in Western European countries for much of the $20^{\text {th }}$ century (Olivetti and Petrongolo, 2016). This historically subordinate role is reflected in that only $5 \%$ of entries in the Spanish Biographical Dictionary correspond to women (Real Academia de la Historia, 2018).

\footnotetext{
${ }^{3}$ Regarding the symbolic power of language, linguists consider that it may influence and constraint our thinking (Ginsburgh and Weber, 2020). Interestingly, Mavisakalyan (2015) finds that countries with gender-intensive languages have lower female labor force participation, and that speakers of these languages have a higher prevalence of gender-discriminatory attitudes. Galor et al. (2020) show that the presence of grammatical distinction based on gender, and its association with gender bias, has an adverse impact on the educational results of women.

4 Some examples include "Toponomastica femminile" (Italy), "Las calles de las mujeres" (international), "A tu nombre" (Uruguay), "Merezco una calle" (Spain), and "Rehov MiShela" (Israel). As the French group "Osez le Féminisme!" put it in a performance in which they symbolically rename 60 streets in Paris, "street names attest to our history: they belong to a political choice, revealing the values that the city wishes to embody" (The Independent, August 27, 2015).
} 
Since the transition to democracy, the so-called "state feminism" has promoted a quick recovery of women's rights (Bustelo, 2016). Currently, the Gender Equality Index is 72 for Spain in 2020, ranked the eighth among 28 European countries (EIGE, 2021). Despite this recent notable improvement, the past weighs heavily upon the street map, with women being vastly underrepresented in urban toponyms. This has given rise to some awareness-raising initiatives such as the educational project "I deserve a street", followed by schools in hundreds of Spanish towns, and specific actions carried out by feminist groups. ${ }^{5}$ As a noteworthy measure, some city councils have taken advantage of the renaming of Francoist streets to favor the recognition of women in the street map.

After providing this social and political background, we next describe the most outstanding characteristics of the Spanish street name system. First, the Spanish street map is largely made up of commemorative names, amounting to approximately 54\% of the total (Oto-Peralías, 2018). Regarding streets referring to people, it is generally possible to identify their gender because they usually contain both the forename and surname of the commemorated person (sometimes even additional data such as the occupation, title, etc.). This characteristic is not common to all countries since in some of them forenames are rarely included in street signs. To get a broader view of country differences in street name systems, we analyze a randomly selected sample of 100 streets in ten major European cities. Among streets named after people, the percentage of them containing forenames goes from $18 \%$ in Vienna to $94 \%$ in Rome (the value for Madrid being $83 \%$ ). ${ }^{6}$ As discussed later, the applicability of our methodology to countries where full names are rarely included in street signs would require some adjustments to the algorithm.

Finally, concerning regulatory aspects, the power to name belongs to local governments. Some town councils, particularly in large municipalities, issue ordinances regulating the procedure and criteria to name streets, while in other cases there is no such regulation. After conducting a review of the ordinances for a sample of 34 Spanish towns and cities, we find some principles that tend to prevail. ${ }^{7}$ First, there is a preference for the preservation of existing names, so that any change must be well justified. The wide adoption of this criterion explains the little variation in established street names, favoring the maintenance of the status quo. ${ }^{8}$ Second, priority is given to people who made significant contributions to the municipality and, in several large cities, only deceased persons can be commemorated. It is worth noting that the criterion of commemorating deceased persons delays the catch-up of female personalities in the streetscape as women have only recently had wide access to prestigious professions. Third, it is also common to forbid naming streets after senior government officials and city councilors -the former arguably to avoid patronage

\footnotetext{
${ }^{5}$ Information about the project "I deserve a street" is available at https://www.merezcounacalle.com/. An example of toponymic activism was the performance \#womenincities where twelve streets were temporally renamed after female figures in Barcelona (Molina, 2017).

${ }^{6}$ See Supplementary Material I (Supp. Mat. I) for more details.

7 See Supp. Mat. I for details.

${ }^{8}$ Buchstaller et al. (2021) provide an analysis of the arguments against street renaming, most of them being of administrative-pragmatic nature.
} 
and the latter conflict of interests.

\section{Measuring gender bias through street names}

\subsection{Data}

Our main dataset is the Electoral Census Street Map provided by the Spanish Statistics Office (INE, 2020). This dataset contains the list of Spanish streets and roads, indicating their name, type (avenue, street, square, etc.), and municipality code. An important advantage of this dataset is that it provides data from 2001 to 2020 (except 2002 and 2003), thereby allowing temporal analysis. The full dataset (2001-2020) contains almost 15 million streets, which divided by 18 years renders an average of 830,000 per year. A limitation of this data source is that, as the street map comes from an electoral census, it only includes streets where there are electors registered. We have checked with an alternative dataset that the potential bias arising from this is of minor importance (see Supp. Mat. II for details).

The Electoral Census Street Map includes a unique code for each road. This number allows us to identify new streets and streets that have been renamed. When a road with a new identifier number appears in a given year within a municipality, we code this street as a new street. Relatedly, when a street with the same identifier changes its name, it is coded as a rename. According to this, during the period 2001-2020 there have been 174,022 new streets and 38,430 renames. The total variation in streets between 2001 and 2020 is 154,636, which does not match the number of new streets because some streets disappear from the dataset when there are no electors living there anymore. This latter figure (the net growth of streets) amounts to the $21.5 \%$ of the number of streets in 2001. For comparison purposes, Spain's population growth during the same period was somewhat smaller, $15.4 \%$.

\subsection{Construction of the indicator}

The street-name indicator of female share is defined as:

$$
F S_{m, y}=\frac{F_{m, y}}{M_{m, y}+F_{m, y}} \times 100
$$

where $M_{m, y}$ and $F_{m, y}$ capture the number of streets in municipality $m$ and year $y$ containing names referred to men and women, respectively.

The most challenging task is to identify whether a street has a male or female name. For this purpose, we develop a text analysis algorithm to classify streets according to their gender, if any. We adopt a binary (male-female) conception of gender. Our approach is culturally based because we infer gender from people's names, and therefore does not necessarily correspond to biological sex. While this binary notion may be at odd with the existing diversity of gender identities and recent government regulations in some countries, we follow it by practical reasons. Otherwise, it would be unfeasible to infer gender exclusively from personal names, needing detailed biographical information about every person commemorated. 
The classifier algorithm is based on a dictionary-based method and implemented as a rulebased system following five steps, which are represented in Figure $1^{9}$ :

i) We collect the 1,000 most frequent male and female forenames in Spain and check whether streets contain any of them. This produces a preliminary classification of male and female streets. ${ }^{10}$

ii) To avoid "false positives", we need to tackle ambiguous names. This is important because many forenames can refer to both a person and something else. Examples are "Israel" and "Rosa", which may also refer to a country or a flower (or color). We proceed by first revising the previous lists of the 1,000 most frequent forenames to detect the ambiguous ones, and then excluding streets that have an ambiguous forename and do not contain a surname or a compound forename. That is, we consider that ambiguous names that are not accompanied by a surname or another forename do not refer to a person.

iii) We correct streets containing both a male and a female forename, which happens either because a same forename is used for both men and women (e.g., "Andrea") or due to compound forenames formed by a male and a female name (e.g., "José María"). While in the first case streets are excluded, in the second the gender of the street depends on the position of each forename (if the male forename is placed before the female one, it is considered a male name, and vice versa).

iv) To address "false negatives", we create lists of male and female words such that if a street name contains one of these terms, it will be coded as male or female. For example, there are many streets named "Cervantes" after the famous writer, but they are not classified as male in step 1 because they do not contain his forename. Therefore, it is crucial to create lists with this and other names to assure that these streets are correctly classified. For the construction of these lists, we gather data from Oto-Peralías (2018) and Yu et al (2016), as well as from a training dataset made up of 10,000 manually-classified streets. The resulting lists of terms contain keywords such as "don"/“doña" [Sir, Madam] and "duque"/"duquesa" [duke, duchess], and nicknames and surnames of famous figures such as "Goya" and "Cervantes".

v) Religious streets related to God, Christ, Virgin Mary (and her apparitions), apostles, and saints are not taken into account and consequently removed. These names are relatively more frequent among female streets and could bias the relevant female share as streets named -for instance- after Virgin Mary (very common in Spain) are not commemorating relevant figures from the point of view of modern, egalitarian gender roles. Nonetheless, as an alternative measure of the female share, we also keep religious streets.

\footnotetext{
${ }^{9}$ See Supp. Mat. III for a more detailed description of these steps.

${ }^{10}$ These lists are long enough to include most of the names of all Spanish linguistic regions. However, we acknowledge that for some regions, particularly the Basque country, the algorithm may be less accurate due to relatively infrequent Basque names, producing more false negatives. In any case, as discussed below, if errors identifying male names are similar in relative magnitude to errors identifying female names, they do not bias the female share indicator.
} 


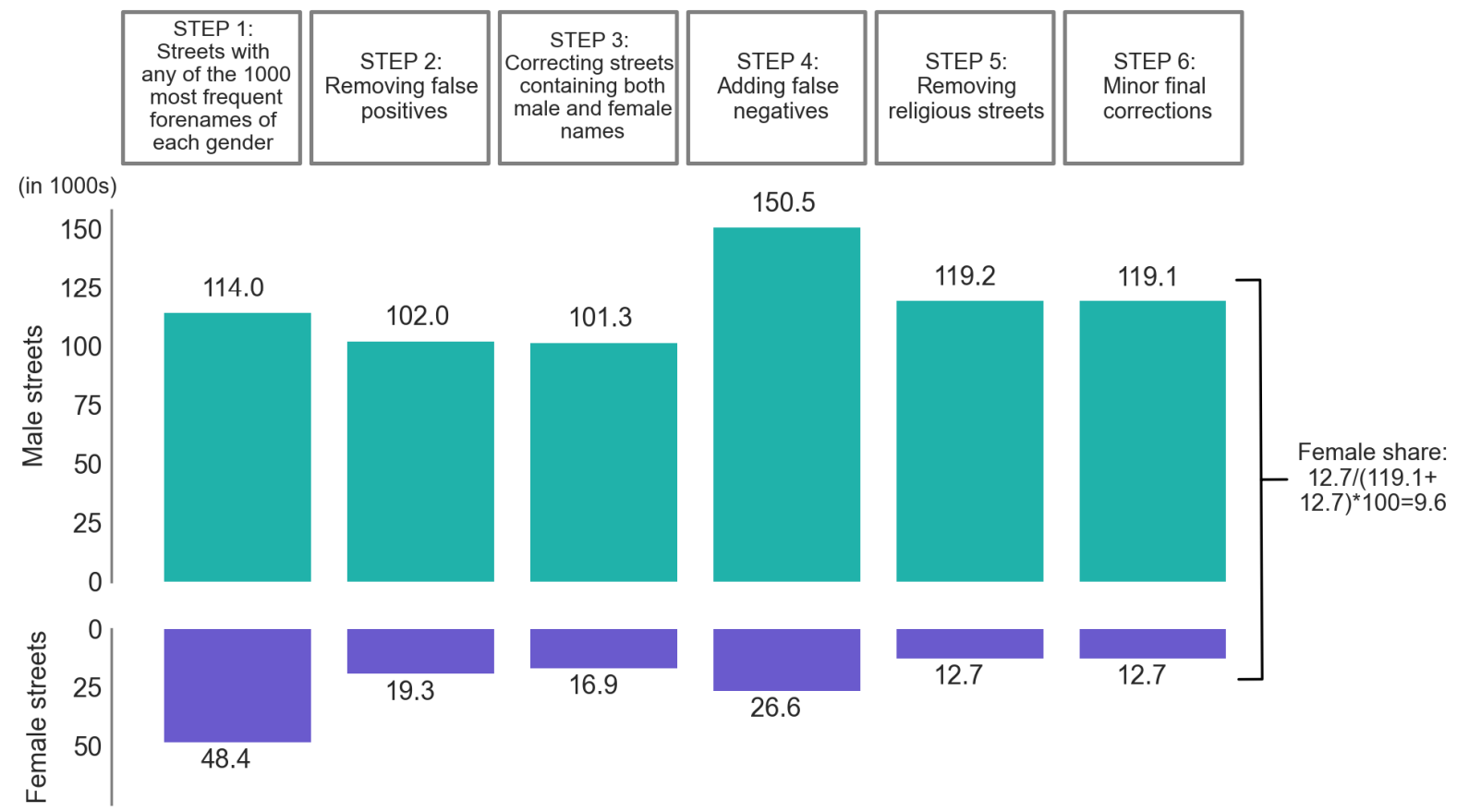

Notes: This figure represents the steps of the classifier algorithm. The data correspond to the 2001 street map, made up of 719,585 streets (INE, 2020).

Figure 1. Diagram of the classifier algorithm.

\subsection{Validity of the indicator}

This section assesses the validity of the indicator, that is, whether its measurement is close to the real value. For this purpose, we construct a test dataset, made up of 5,000 streets selected randomly, which we classify manually. Table 1 shows the performance of the classifier algorithm against the test dataset. The accuracy is very high for both male and female streets (97.3 and $99.2 \%$, respectively). Regarding the other coefficients, the weakest results are for sensitivity due to the presence of false negatives, which are more common than false positives. This is hardly surprising given the local nature of the data, where many streets are named after local people using their nicknames or surnames. The last column reports a coefficient that we call "deviation rate", which is calculated as cases identified as positives divided by real positives minus one. This is an important coefficient because if it is similar for male and female streets, then the female share will also be similar to its "true" value. This is actually the case here, as the difference between the deviation rates is about one percentage point (pp.). Consequently, the female share based on the classifier is very similar to the one based on human-made classification (12.32 vs $12.48 \%$ ). Thus, the classifier algorithm is not error-free, but to the extent that errors identifying female streets are similar in relative magnitude to errors identifying male streets, errors offset one another and do not bias the female share. 
Table 1. The performance of the classifier algorithm against the test dataset

\begin{tabular}{|c|c|c|c|c|c|}
\hline & Precision & Sensitivity & Specificity & Accuracy & Deviation rate \\
\hline Male streets & 96.49 & 87.69 & 99.32 & 97.28 & -9.12 \\
\hline Female streets & 87.50 & 78.40 & 99.71 & 99.18 & -10.40 \\
\hline \multicolumn{6}{|c|}{ Female share } \\
\hline \multicolumn{2}{|c|}{ Classifier algorithm $\rightarrow$} & 12.32 & & & \\
\hline \multicolumn{2}{|c|}{ Human-made classification $\rightarrow$} & 12.48 & & & \\
\hline
\end{tabular}

The probability of a small difference in the deviation rate between male and female streets is positively related to the sample size. Supp. Mat. IV presents the results of a simulation exercise with sample sizes ranging from 10 to 500 . Panel $A$ in Figure $S 1$ shows that the larger the sample size, the smaller the difference in the deviation rate between male and female streets. Consistently, Panel $B$ depicts a similar negative relationship with the mean absolute error of the female share. Interestingly, this graph gives us a measure of the expected error depending on the number of streets. For instance, for a sample of 10 streets, the expected difference with the "true" female share is almost 5 percentage points (pps.), while it declines to 3 pps. for a sample of 100 streets.

To further assess the validity of the classifier algorithm, we compare our estimates with results of case studies conducted for specific cities in Spain. We collect data on 26 estimates of the female share for a variety of cities and years from several sources. Figure S2 (in Supp. Mat. IV) represents the relationship between the estimates of our classifier algorithm and those of case studies. Remarkably, the correlation between both measures is very strong (0.94). In addition, the classifier does not systematically over- or underestimate the female share, as errors are both above and below the 45-degree line.

\section{Female share: results}

\subsection{Main results of the female share indicator}

We begin by presenting the results for the whole country. Panel A of Figure 2 shows the evolution of the female share from 2001 to 2020 for all existing streets. The baseline indicator (solid line) goes from $9.6 \%$ in 2001 to $12.1 \%$ in 2020 , thereby indicating a strong gender imbalance in the street map and a slow progress towards parity. When we take a more flexible approach regarding religious streets and include streets named after saints, the female share increases roughly $1 \mathrm{pp}$;; and when considering all religious streets, the female share increases about 4 pps. Panel B focuses on new and renamed streets. The female share is significantly higher and more volatile, ranging between $13.6 \%$ in 2015 and $24.5 \%$ in 2020 . While these values are higher, they are still far from $50 \%$ that would imply parity.

Regarding the frequency distributions of male and female streets, the concentration in female names is notably higher: the relative frequency of the most common female name (the politician 
and women's rights advocate Clara Campoamor) is $2.3 \%$, while that of the most common male name (Cervantes) is $1.3 \%$. Similarly, the top-10 female street names concentrate $13.2 \%$ of all female streets, while the top-10 male ones concentrate $7.4 \%$ of male streets. This fact suggests that local authorities tend to resort to famous nationwide figures to a larger extent for female names than for male names.

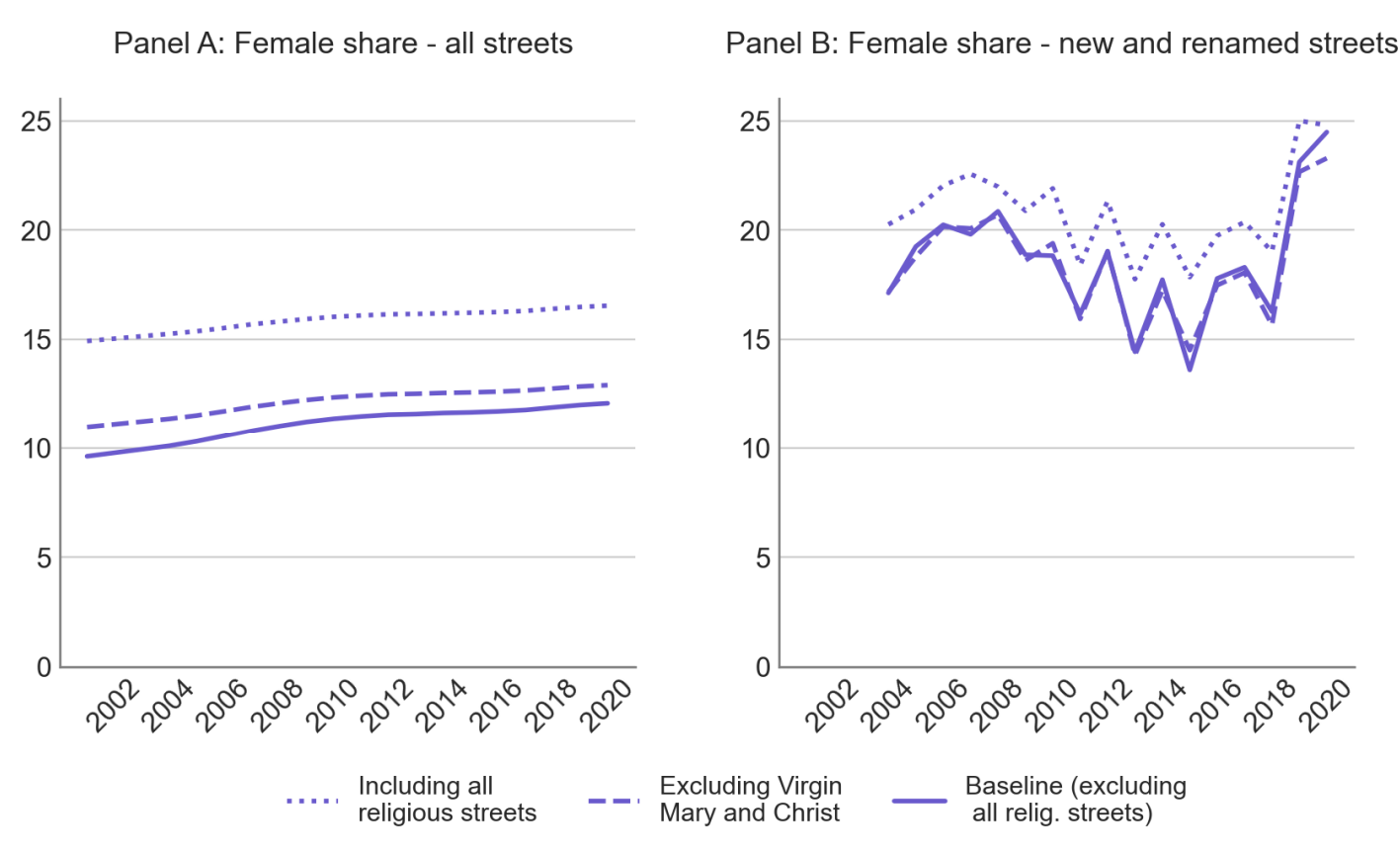

Figure 2. Main results at the national level.

The main advantage of street names to measure social phenomena is its spatial granularity. It allows the study of the phenomenon of interest at the regional and local levels. Panel A of Figure 3 shows the provincial values of the female share in 2020. There is substantial spatial variation, with values ranging from $8.4 \%$ (Soria) to $16.9 \%$ (Granada). Panel B depicts a positive relationship between the female share in 2001 and that for new and renamed streets during the period 2001$2020(p=0.49$ ). Thus, provinces with a higher percentage of female streets in 2001 have on average named more streets after women during the next 20 years, reflecting some persistence or inertia over time. Finally, Panel $C$ represents the female share at the city level, focusing on towns equal to or larger than 10,000 inhabitants for visualization purposes. It is common to find neighboring cities with different female shares, thereby indicating a significant local variation. ${ }^{11}$

${ }^{11}$ Figure S3 in Supp. Mat. V provides more results at the city level. 

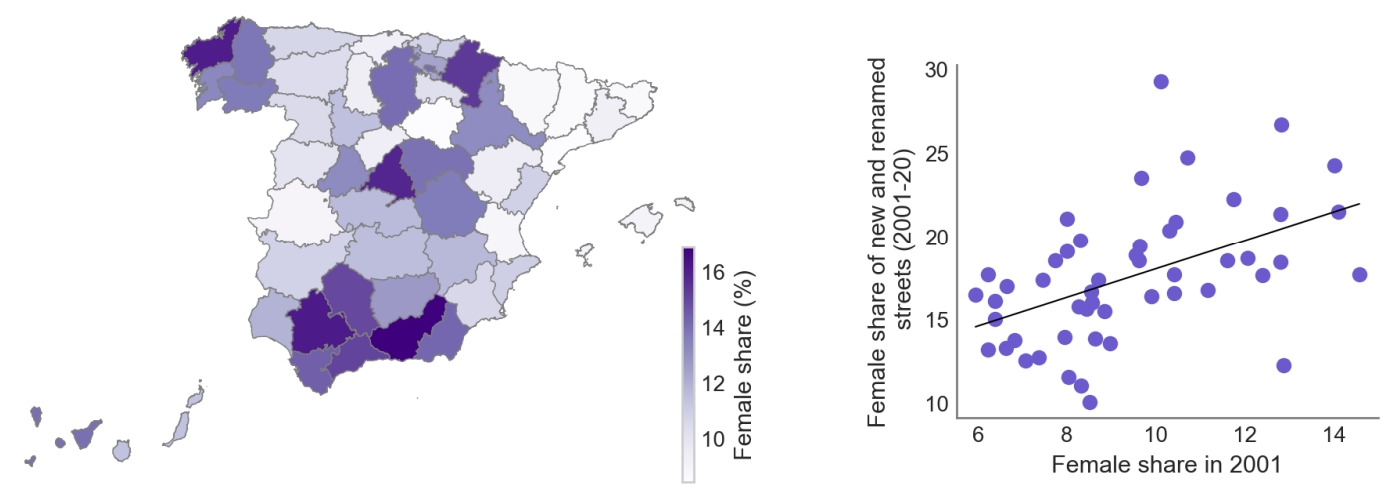

Panel C: Female share of street names in 2020: municipality values

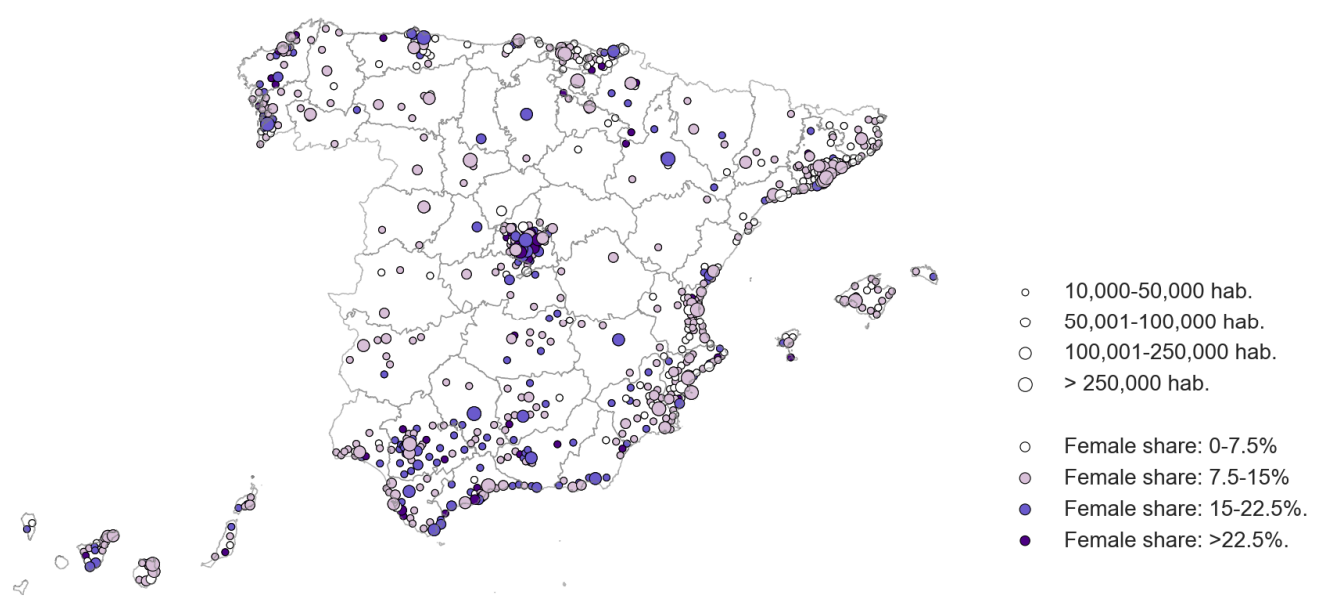

Notes: For visualization purposes, Panel C excludes municipalities smaller than 10,000 inhabitants in 2020 .

Figure 3. Female share at the provincial and city levels.

\subsection{Intra-urban location of male and female named streets}

Streets differ in several dimensions such as their size and importance within the urban network, which affects the meaning and scope of the commemorated names as well as the public perception of them (Alderman, 2003). A central avenue in the city provides much more geographic scale to a name than a small street in a peripherical neighborhood. In the first case, the name will reach much more people than in the second. We systematically analyze the intra-urban location of male and female streets through their length and centrality. For this task, we extract data on streets and municipalities town halls from OpenStreetMap (OSM, 2020), rendering a dataset of 5,428 municipalities with approximately 560,000 streets in total. This represents almost $70 \%$ of all Spanish towns and streets.

We measure the centrality of each street following two steps: first, we compute the distance from the street representative point (i.e., inner midpoint) to the municipality town hall; and second, we calculate, within each municipality, the quintile rank of each street in the distribution of distance to the town hall. Panel A in Figure 4 aggregates streets by their quintiles and represents the female 
share of each one. There is a clear spatial pattern in terms of centrality: the proportion of female streets increases by more than half as we move away from the town center, rising from $9.4 \%$ in the first quintile to $14.6 \%$ in the last one. Consistent with this, Panel B shows that the distribution of male streets is more concentrated in the first quintiles than the distribution of female streets. For instance, $23.1 \%$ of male streets are in the first quintile and only $12.4 \%$ in the last one; while for female streets these percentages are 18.7 and $16.6 \%$, respectively. Looking at this pattern from a different angle, the left plot in Panel $\mathrm{C}$ shows that female streets are on average further away from the center than male streets (2,342.8 vs $1,956.7$ meters). Thus, these results confirm the partial evidence found in case studies indicating that female streets tend to be located in less prominent areas.

We also analyze whether gendered streets differ in length. The right plot in Panel $C$ shows that female streets are slightly longer than male streets (251.4 vs 243.3 meters). Although this might seem counter-intuitive, it is explained by the fact that male streets are closer to the center and streets in the center are shorter. Regarding the latter, the average street length in the first and last quintiles in distance to the center is 186 and 343 meters, respectively. When comparing quintile by quintile, male streets are slightly longer than female ones in the first three quintiles, while the opposite is true in the last two. Overall, differences in length among gendered streets appear to be of minor importance. ${ }^{12}$

Panel D compares alternative versions of the female share indicator. First, we use street length as a weight to compute the indicator, which is equivalent to calculate the proportion of female street meters over the total length of all male and female streets in meters. When doing this, the female share only increases 0.3 pps. (from 11.36 to $11.7 \%$ ). Second, we create a centrality score for each street equal to 6 minus the quintile rank (so a higher value is given to streets close to the center), and then use this score as a weight to calculate the female share indicator. This new measure renders a proportion of female streets $0.7 \mathrm{pps}$. lower than the baseline indicator (10.65\%). Finally, we take into account both street length and centrality simultaneously by weighting each street by the product of its length and quintile score. The female share remains however virtually the same.

All the previous results suggest that the main driver of gender inequality in the streetscape is the much higher frequency of male names. The centrality of streets further accentuates this pattern, as male streets tend to be in more prominent areas, but taking into account this dimension has a moderate impact on the big picture. We further check that there exists a high municipalitylevel correlation between the baseline female share indicator and alternative measures weighted by street centrality and street length (the correlation coefficient being 0.74 and 0.90 , respectively).

Finally, the granularity of the data enables us to zoom in on cities and visualize the gender composition of the street map, and even to calculate the female share at the city district level. Figure 5 draws the gendered street maps of Spain's largest cities. These visualizations, fed with

12 The average length of male streets is $186,227,242,272$, and 340 meters for quintiles 1 to 5 in distance to the town hall, respectively. The corresponding values for female streets are 180, 220, 231, 282, and 361 meters. 
the output of our classifier, are valuable tools to communicate and make visible the research question addressed, clearly showing patterns and trends, and thereby favoring a public reflection.

Panel A: Female share by street centrality quintiles

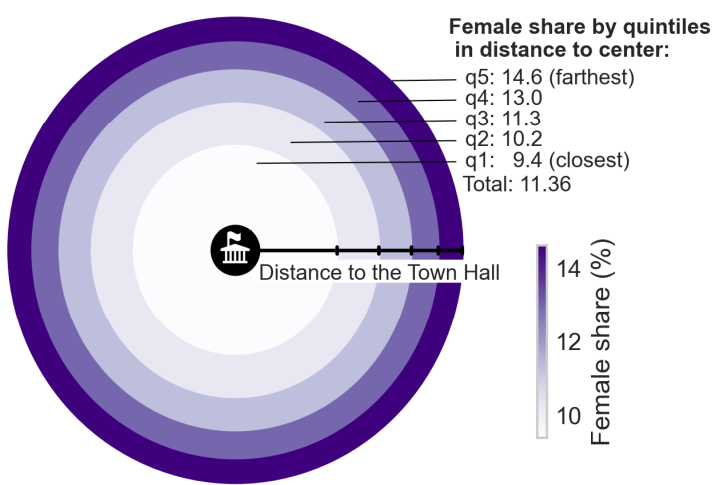

Panel C: Average distance to city center and average length
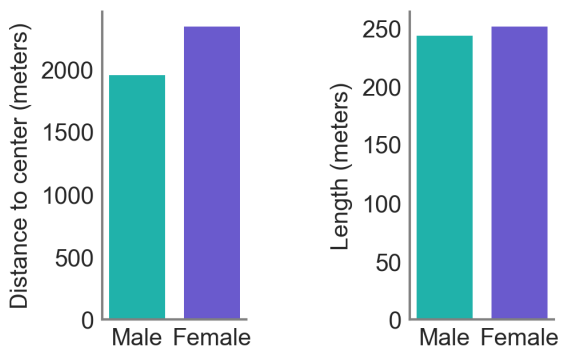

Panel B: Distribution of streets by centrality

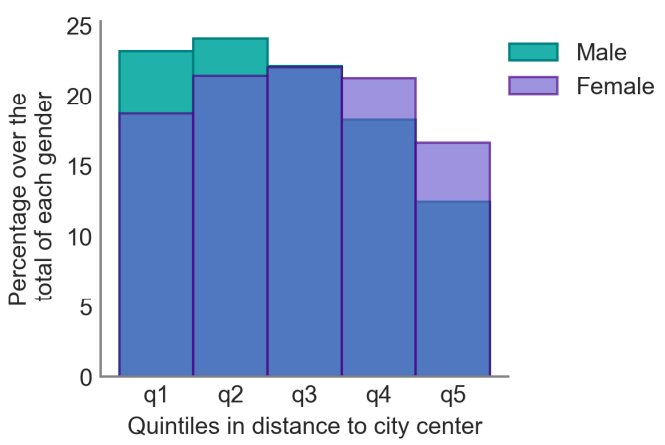

Panel D: Comparison among different versions of the female share indicator

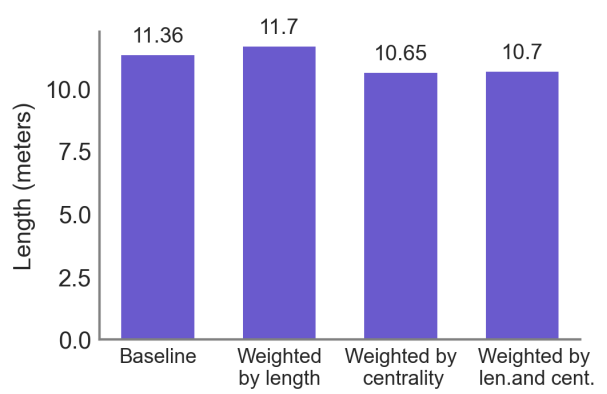

Notes: Panel A represents the female share calculated for each quintile in distance to the city center (identified by the town hall). Quintiles are initially calculated for each town and then aggregated together. Panel B depicts the distribution of male and female streets by quintiles in distance to the city center. Panel C shows the average distance from the street representative point to the town hall (left graph) and the average street length (right graph). Panel D shows the comparison between the baseline female share indicator and analogous measures weighted by street centrality and street length. Data: OSM (2020).

Figure 4. Narrowing down gendered streets: centrality and length.

\subsection{The relationship of the female share with socioeconomic indicators}

This section analyzes the relationship of the female share with several socioeconomic indicators at the municipality level. This exercise is interesting to know what factors are related to egalitarian naming policies. In addition, to the extent that the commemorative decisions of the local community reflect its cultural values, this exercise gives us clues about the determinants of the population attitudes towards gender roles.

Figure 6 focuses on variables related to a greater or lesser extent to gender equality at the local level. To begin with, one would expect more egalitarian attitudes towards gender roles in bigger towns, with a young and educated population. This is exactly what Panels $A$ to $C$ show. Considering average age (Panel B), the fitted line implies that an increase of 10 years in average age is associated with a decrease of 2 pps. in the female share. This is a sizeable variation given 


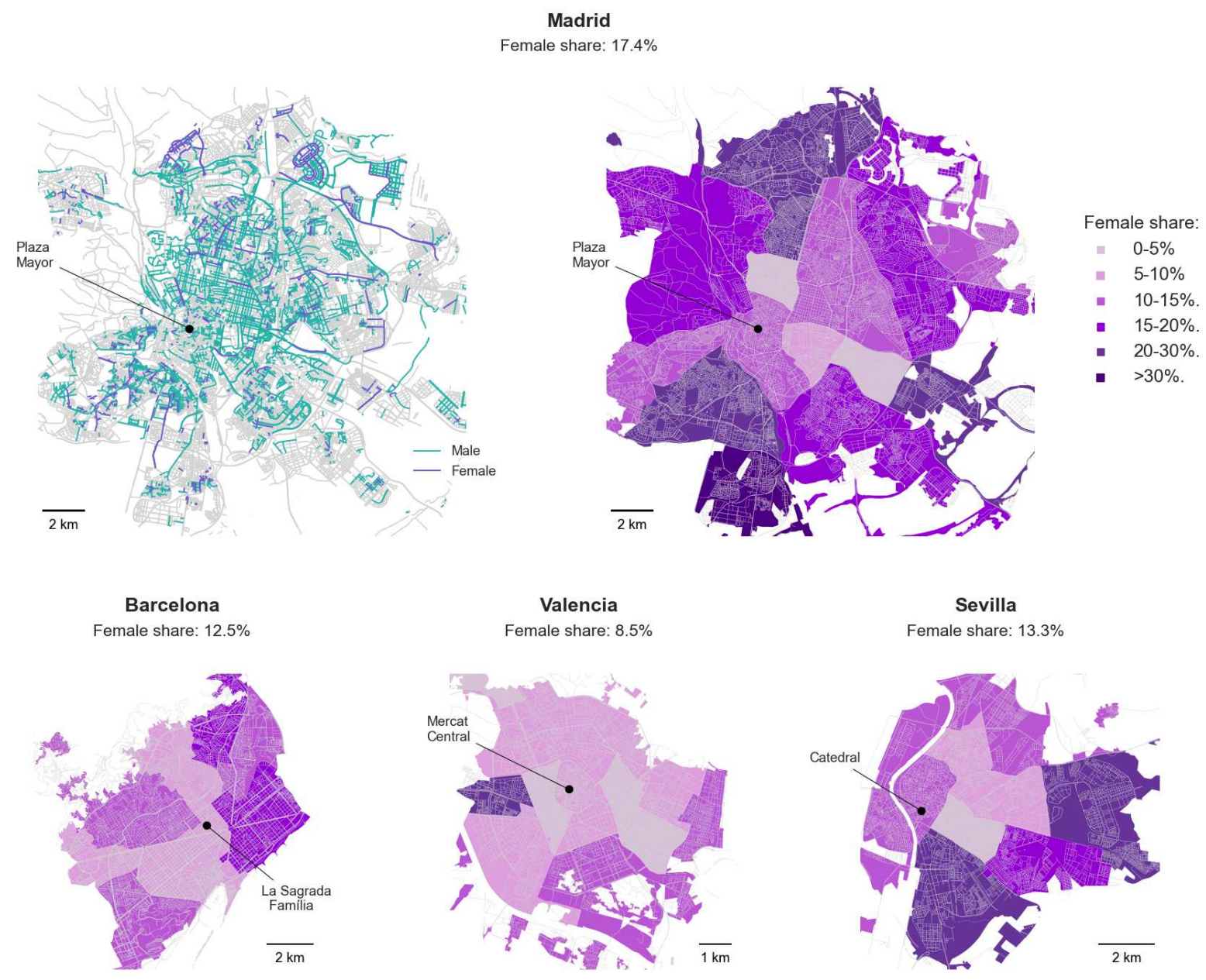

Notes: Data sources: OSM (2020) and Digital Cartography of the Electoral Census (INE).

Figure 5. Female share in Spain's largest cities.

Panels $D$ to $F$ analyze the correlations with: i) the service sector share in employment, ii) the percentage of separated and divorced people, and iii) the percentage of residents born in the municipality. Regarding the first variable, the service sector has been (and still is) the most feminized sector, implying more chances for women to work outside and play relevant public roles. The second variable, the percentage of separated and divorced people, is also expected to be higher in areas where women are more independent. Concerning the last variable, a lower percentage of residents born in the municipality implies a more dynamic place, with weaker ties with older generations and possibly less traditional attitudes towards gender roles. Interestingly, the female share is positively correlated with the first two variables, while the correlation is not clear in the latter case.

${ }^{13}$ All variables are measured in 2001. The female share is censored at the $95^{\text {th }}$ percentile to mitigate the influence of abnormally high values. Variable definitions, sources, and descriptive statistics are provided in Supp. Mat. VI. 
Panels G to I include indicators that explicitly aim to capture gender (in)equality in several dimensions for which data is available at the local level. These are the gender gaps in: i) labor force activity rate, ii) percentage of population with secondary or higher education, and iii) percentage of population doing housework. Remarkably, there is a clear negative relationship between the female share in street names and these measures of gender gap. Considering the gender gap in housework (Panel I), an increase of $25 \mathrm{pps}$. (moving from percentile $20^{\text {th }}$ to $80^{\text {th }}$ ) is associated with a decrease of $1 \mathrm{pp}$. in the female share. ${ }^{14}$

To further assess the link between the female share indicator and the population attitudes towards gender roles, we collect survey data from the ISSP Family and Changing Gender Roles modules, corresponding to the years 1994, 2002, and 2012. These three surveys have six questions that can be combined to create a composite indicator of attitudes towards gender roles. ${ }^{15}$ There are 2,732 individuals distributed across 70 cities for which we know the municipality code. This enables us to analyze whether the female share of the respondent's municipality is related to her gender views. We use the following hierarchical linear model estimated via ordinary least squares:

$$
Y_{i, c, r}=\alpha+\beta \cdot I n d_{i, c, r}+\delta \cdot C_{c, r}+\gamma \cdot F S_{c, r}+\eta \cdot R_{r}+\varepsilon_{i, c, r}
$$

where $Y_{i, c, r}$ is the composite indicator of gender views of individual $i$ living in city $c$ located in region $r$. Indi,c,r is a vector of control variables at the individual level (sex, age, marital status, educational level, socioeconomic status, and interview year); $C_{c, r}$ is a vector of control variables at the city level (log population in 2001 and number of streets); $F S_{c, r}$ stands for the female share in street names; $R_{r}$ refers to a set of 17 binary variables, one for each Spanish region; and $\varepsilon_{i, c, r}$ is the error term. The coefficient of interest is $\gamma$, which captures the effect of $1 \mathrm{pp}$. increase in the female share.

Table 2 reports the results. Column 1 shows a positive correlation between the female share indicator and gender views, which is statistically significant at $10 \%$. Columns 2 and 3 add individual-level and municipality-level control variables, respectively, with little impact on the coefficient of interest. Column 4 further includes a set of 17 binary indicators, one for each region, which makes up our baseline model. This model only exploits variation in interview responses within regions but not across regions. The coefficient is now larger and more precisely estimated. Moving from the town in the sample with the lowest female share (1.3\%) to the one with the largest (38.46) is associated with an increase of 0.49 in gender views. Column 5 includes a set of 50 binary indicators, one for each province, which does not alter the previous results. All in all, these results suggest that people living in towns with a higher female share tend to have more egalitarian gender views.

\footnotetext{
${ }^{14}$ Figure 6 reports simple bivariate correlations, but we show in Supp. Mat. VII that they are robust when controlling for a set of 17 region binary variables and the log of town population, as well as when focusing on towns with more than 100 streets (where measurement errors are lower).

${ }^{15}$ See Supp. Mat. VIII for details on the construction of the indicator.
} 

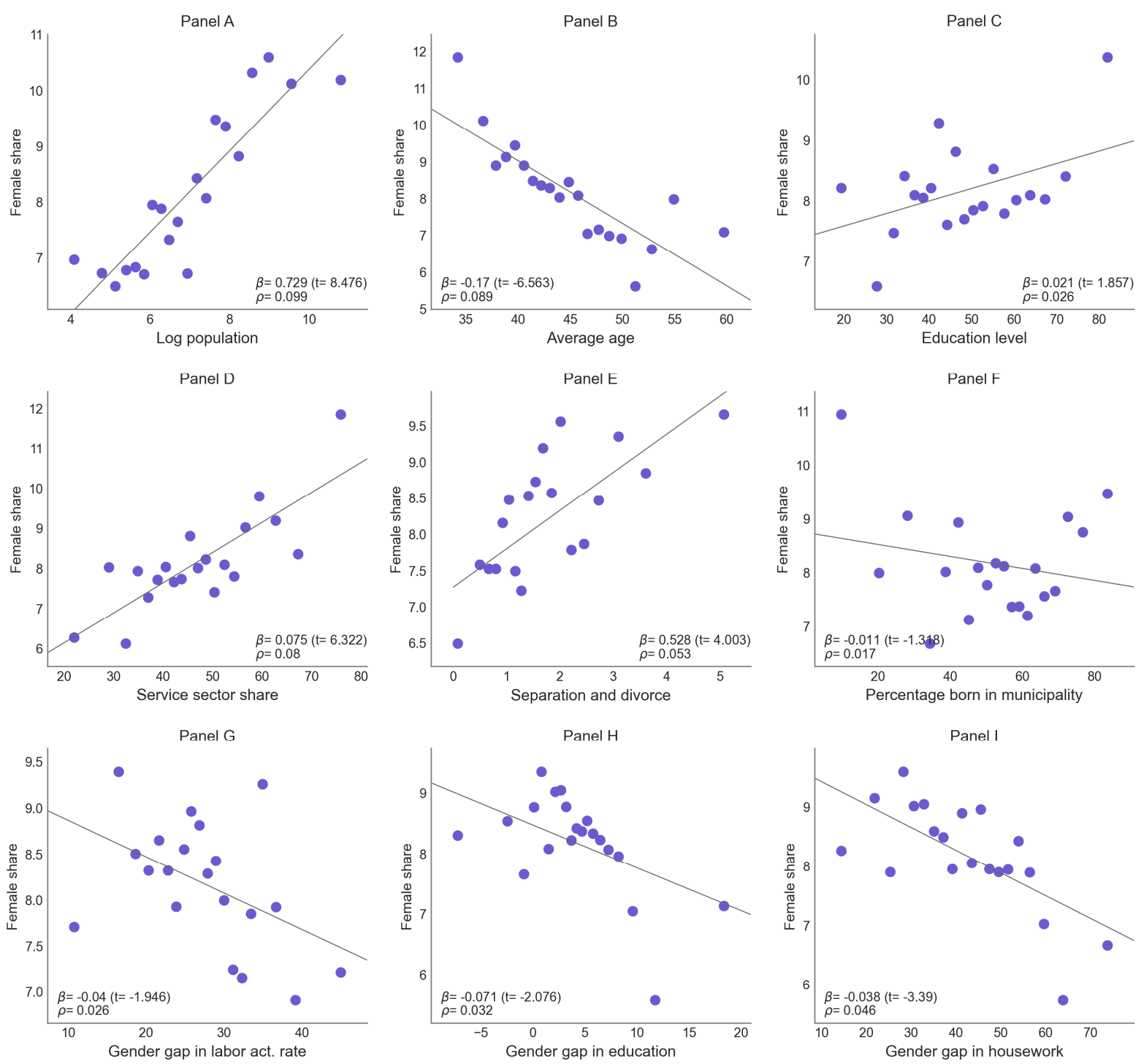

Notes: The figure shows binned scatter plots along with the best fitted line. All data correspond to 2001. The female share is winsorized at the 95th percentile.

Figure 6. The relationship of the female share with socioeconomic indicators at the municipality level.

Table 2. The female share in street names and attitudes towards gender roles

\begin{tabular}{lccccc}
\hline & $(1)$ & $(2)$ & $(3)$ & $(4)$ & $(5)$ \\
\hline Female share in 2001 & $0.0102^{*}$ & $0.0075^{*}$ & $0.0072^{*}$ & $0.0132^{\star \star *}$ & $0.0115^{\star * *}$ \\
& $(0.0055)$ & $(0.0045)$ & $(0.0043)$ & $(0.0045)$ & $(0.0035)$ \\
& & Yes & Yes & Yes & Yes \\
Individual level controls & & & Yes & Yes & Yes \\
City level controls & & & & Yes & \\
17 region dummies & & & & & Yes \\
50 province dummies & & & & & 2660 \\
Number of observations & 2850 & 2660 & 2660 & 2660 \\
R-squared & 0.001 & 0.200 & 0.200 & 0.215 & 0.235 \\
\hline
\end{tabular}


Notes: Individual level controls include sex, age, marital status, educational level, socio-economic status, and interview year. City level controls include log population in 2001 and number of streets. All variables refer to year 2001. Variable definitions are provided in Table S4 (Sup. Material VI). Standard errors clustered at the municipality level in parentheses. The variance inflation factor for 'Female share in 2001 ' is $1,1.01,1.14,2.48$, and 3.09 in columns 1 to 5 , respectively, indicating that collinearity is not affecting its coefficient. ${ }^{*} p<0.1,{ }^{* *} p<0.05,{ }^{* \star *} p<0.01$.

Finally, we explore whether places where women have historically played more prominent roles are more likely to commemorate them in their streets. To measure the historical prominence of women in society, we use the Spanish Biographical Dictionary (Real Academia de la Historia, 2018), a monumental work containing more than 50,000 historical figures. We calculate the percentage of dictionary entries in each province referring to women. Figure S7 (in Supp. Mat. IX) shows that there is a clear positive (province-level) correlation between the female share indicator and the percentage of female entries. This correlation is robust to the inclusion of control variables such as per capita GDP and total population.

Before concluding this section, it is worth noting that this analysis only tries to uncover relationships of naming patterns with other variables. Yet, we can argue that causality mainly goes from the socio-economic and political features of municipalities to street names, in the sense that city and town councils name streets based on their local political preferences. However, as noted in Section 2, the prevalence of male names can also reinforce the values that shape political preferences, thus informing future street naming practices.

\section{Discussion and conclusions}

This article develops a methodology to quantify gender bias in street names through the use of computational tools of text analysis. This allows to measure gender bias in urban toponyms on a massive scale. We apply the methodology to 15 million roads that make up the Spanish street map for the period 2001-2020. The female share (the percentage of female streets over the total male and female streets) goes from $9.6 \%$ in 2001 to $12.1 \%$ in 2020 . Considering new and renamed streets, the female share is higher but still far from $50 \%$ that would imply parity. Beyond its intrinsic value as a measure of the symbolic relevance given to women in the cityscape, our analysis shows that the female share indicator is related to cultural values and attitudes of gender equality.

This study expands the critical urban toponymy literature by systematically quantifying gender bias in street names, uncovering its intra-urban spatial patterns, and analyzing how naming patterns fit with the socio-cultural characteristics of cities. This is a significant addition to an underresearched topic in this literature since, as Rose-Redwood et al. (2018) pointed out, "the study of the gender politics of street naming is still a woefully neglected theme in urban studies and critical toponymic scholarship" (p. 13). Despite some other recent works (Bigon and Zuvalinyenga, 2021), more research is needed to improve our understanding of important questions such as how naming practices interact with social activism and the political empowerment of women. In addition, this study provides a new quantitative methodological approach to the place name literature, which is largely dominated by qualitative ethnographic analysis.

Before concluding, three points are worth discussing. The first one has to do with the precision 
of the indicator. As mentioned in Section 4, the larger the size (number of streets) of the town, the more precise the indicator. From 200 streets onwards, the absolute error is expected to be below 2.5 pps. Testing our results against a test dataset and case studies of specific cities provides reassurance to our methodology, but the algorithm is not error-free, and errors might be large for particular cases. Therefore, caution is needed when interpreting the results in an individual manner, particularly for small towns.

The second point is related to the applicability of this methodology to other countries. The classifier algorithm is based on dictionaries of terms with Spanish names. When applying it to other countries, one needs to collect data to feed these dictionaries with the most common male and female names, as well as keywords denoting gender. Given the nature of the task, the methodology is more easily applicable to languages with a strong gender system (with grammatical distinctions based on gender) like Spanish than to gender-neutral ones like Finnish. Similarly, it is more applicable to countries where street names commonly contain full names than to those where streets normally only include surnames (like the UK). In the latter, the classifier algorithm should be redesigned, shifting from a rule-based system to a more probabilistic one, which may take advantage of machine learning techniques.

Finally, although this article's main purpose is positive rather than normative, a more balanced representation of men and women in the cityscape seems to be a desirable outcome for societies that aspire to become more egalitarian. Our methodology can be a useful tool for urban management and social movements to monitor progress towards this goal. While increasing the female share in new streets is the easiest way forward in this regard, our analysis shows that some renaming is needed to significantly improve the presence of women quantitatively (number of streets) and qualitatively (prominence of streets). Moreover, street renaming may fuel a necessary public debate on the subject. From a research perspective, the female share indicator can be used as a convenient measure for the analysis of women-friendly policies at the local level. Moreover, it can also be used as a proxy for cultural attitudes towards gender roles, expanding the possibilities of analysis with this novel measure.

\section{References}

Alderman DH (2003). Street names and the scaling of memory: The politics of commemorating Martin Luther King, Jr within the African American community. Area 35(2): 163-173.

Alderman DH (2020). Commemorative Place Naming; To Name Place, To Claim the Past, To Repair Futures. In: Giraut F and Houssay-Holzschuch (eds) Naming the World: The Politics of Place Naming. ISTE-Wiley, forthcoming.

Alvanides S, Buchstaller I and Griese F (2021) Spatiotemporal street name changes in Eastern Germany. In: 29th Annual GIS Research UK Conference (GISRUK), Cardiff, UK, 14-16 April 2021.

Azaryahu M (1996) The power of commemorative street names. Environment and Planning D: Society and Space 14(3): 311-330.

Berg LD and Kearns RA (1996) Naming as norming: 'race', gender, and the identity politics of naming places in Aotearoa/New Zealand. Environment and Planning D: Society and Space 14(1): 99-122.

Bigon L and Zuvalinyenga D (2021) Urban Pulse-Gendered urban toponyms in the global South: a time for de-colonization? Urban Geography 42(2): 226-239. 
Buchstaller I, Alvanides S, Griese F and Schneider C (2021) Competing Ideologies, Competing Semiotics: A critical perspective on politically-driven renaming practices in Annaberg-Buchholz, Eastern Germany. In: Ziegler E and Marten HF (eds) Linguistic Landscapes im deutschsprachigen Kontext. Peter Lang- FAL, pp. 227-258.

Bustelo M (2016) Three decades of state feminism and gender equality policies in multi-governed Spain. Sex Roles 74(3-4): 107-120.

Capdepón U (2020) Challenging the symbolic representation of the Franco dictatorship: The street name controversy in Madrid. History and Memory 32(1): 100-130.

Cavalo LE (2019) Androcentrismo y espacio público: análisis exploratorio sobre la subrepresentación femenina en la nomenclatura urbana de la Ciudad Autónoma de Buenos Aires. Feminismo/s 33: 249-271.

Cooper CA and Knotts HG (2010) Declining Dixie: regional identification in the modern American South. Social Forces 88: 1083-1101.

Drozdzewski D (2014) Using history in the streetscape to affirm geopolitics of memory. Political Geography 42: 66-78.

EIGE (2020) Gender Equality Index: 2020 edition. European Institute for Gender Equality. Available at https://eige.europa.eu/gender-equality-index/2020 (Accessed, 10 July 2021).

Fabiszak M, Buchstaller I, Brzezińska AW, Alvanides S, Griese F and Schneider C (2021) Ideology in the linguistic landscape: towards a quantitative approach." Discourse \& Society, 32(4): 405425.

Fernández V (2004) Memoria de mujeres en el callejero de Madrid. Madrid: Concejalía de Gobierno de Empleo y Servicios al Ciudadano.

Forrest C (2018) What's in a name? A feminist reflection on street name changes in Durban. Agenda 32(2): 53-61.

Fuchs S (2015) An integrated approach to Germanic place names in the American Midwest. The Professional Geographer 67: 330-341.

Galor O, Özak Ö and Sarid A (2020) Linguistic traits and human capital formation. AEA Papers and Proceedings 110: 309-13.

Ginsburgh V and Weber S (2020) The economics of language. Journal of Economic Literature 58(2): 348-404.

González Faraco JC and Murphy MD (1997) Street names and political regimes in an Andalusian town. Ethnology 36(2): 123-148.

Gutiérrez-Mora D and Oto-Peralías D (2021) Gendered cities: studying urban gender bias through street names. OSF Preprints. March 6. doi:10.31219/osf.io/b9n4k.

INE (2020) Callejero de Censo Electoral. Instituto Nacional de Estadística. Available at: www.ine.es.

Liesch M, Dunklee LM, Legg RJ, Feig AD and Krause AJ (2015) Use of business-naming practices to delineate vernacular regions: a Michigan example. Journal of Geography 114: 188-196.

Lombardo E and Meier P (2018) Good symbolic representation: the relevance of inclusion. PS: Political Science \& Politics 51(2): 327-330.

Mamvura Z, Muwati I and Mutasa DE (2018) 'Toponymic commemoration is not for one sex': the gender politics of place renaming in Harare. African Identities 16(4), 429-443.

Mavisakalyan A (2015) Gender in language and gender in employment. Oxford Development Studies 43(4): 403-424.

Mcdowell S (2008) Commemorating dead 'men': gendering the past and present in post-conflict Northern Ireland. Gender, Place and Culture 15(4): 335-354.

Molina S (2017) "Cambia una calle, cambia el mundo". The Urban Activist, March 1. Available at https://theurbanactivist.com/idea/cambia-una-calle-cambia-el-mundo/

Olivetti C and Petrongolo B (2016) The evolution of gender gaps in industrialized countries. Annual review of Economics 8: 405-434.

OSM (2020) OpenStreetMap. Downloaded from Geofabrik. Available at http://download.geofabrik.de/ (Accessed 28 August 2020). 
Oto-Peralías D (2017) What do street names tell us? An application to Great Britain's streets. Available at SSRN: https://ssrn.com/abstract=3063381.

Oto-Peralías D (2018) What do street names tell us? The "city-text" as socio-cultural data. Journal of Economic Geography 18(1): 187-211.

Palonen E (2008) The city-text in post-communist Budapest: street names, memorials, and the politics of commemoration. GeoJournal 73: 219-230.

Real Academia de la Historia (2018) Diccionario Biográfico Español. Available at: http://dbe.rah.es/

Rose-Redwood R, Alderman D and Azaryahu M (2010) Geographies of toponymic inscription: new directions in critical place-name studies. Progress in Human Geography 34: 453-470.

Rose-Redwood R, Alderman D and Azaryahu M (2018) The urban streetscape as political cosmos. In: Rose-Redwood R, Alderman D and Azaryahu M (eds) The political life of urban streetscapes: Naming, politics, and place. Routledge, pp. 1-24, 309-319.

Rusu MS (2020) Political patterning of urban namescapes and post-socialist toponymic change: A quantitative analysis of three Romanian cities. Cities 103, 102773.

Tretter E (2011) The power of naming: the toponymic geographies of commemorated AfricanAmericans. The Professional Geographer 63(1): 34-54.

Weaver R and Holtkamp C (2016) Determinants of Appalachian identity: using vernacular traces to study cultural geographies of an American region. Annals of the American Association of Geographers 106: 203-221.

Yu SL (2014) The production of a gendered space: reading women's landmarks in Anping, Taiwan." Asian Women 30(4): 53-74.

Yu AZ, Ronen S, Hu K, Lu T and Hidalgo CA (2016) Pantheon 1.0, A Manually Verified Dataset of Globally Famous Biographies. Scientific Data 2:150075. [Version 2.0 used]. 